\title{
O QUE TEM O ROCK A VER COM BOURDIEU? CONTRIBUTOS ACERCA DA APLICAÇÃO DA TEORIA DOS CAMPOS AO ROCK ALTERNATIVO PORTUGUÊS
} (1980-2010)

Paula Guerra ${ }^{1}$

\begin{abstract}
Resumo
O principal objetivo deste artigo é analisar as representações sociais do rock alternativo em Portugal entre 1980 e 2010; parte de uma pesquisa mais ampla sobre os 30 anos de modernização do país (a partir do período pósrevolucionário iniciado em 1974), em que o rock alternativo é considerado uma prática social significativa no âmbito da estrutura social, artística e musical do país. Consideramos que o rock alternativo é um assunto que pode ser iluminado pela teoria dos campos de Bourdieu, que utilizamos para explorar a complexidade das relações que substanciam as estruturas subjacentes (de bandas, músicos, agentes, locais de eventos, editoras e promotores) do rock alternativo português. Os dados utilizados são resultado de uma pesquisa de longo prazo realizada entre 2005 e 2010, em que foram realizadas entrevistas em profundidade com mais de 200 indivíduos envolvidos nas esferas de produção e publicação do segmento de rock alternativo português.
\end{abstract}

Palavras-chave: Produção cultural. Rock alternativo. Pop Rock. Campo Social. Bourdieu. Portugal.

\section{What does rock have to do with Bourdieu? contributions on the application of field theory to portuguese alternative rock}

(1980-2010)

\begin{abstract}
The main goal of this article is to analyse the social representations of alternative rock in Portugal from 1980 to 2010. This is part of broader research into the 30 years of modernization of the country (from the post-revolutionary period initiated in 1974), in which alternative rock is regarded as a significant social practice within the scope of the social, artistic and musical structuring of the country itself. We consider that alternative rock is a subject that is illuminated by Bourdieu's theory of fields, and we use it to explore the complexity of the relationships that substantiate the underlying structures (of bands, musicians, agents, venues, record labels and promoters) of Portuguese alternative rock. The data we used is the result of a long-term research project carried out between 2005 and 2010, in which in-depth interviews were conducted with more than 200 participants

\footnotetext{
1 Professora no Departamento de Sociologia da Faculdade de Letras da Universidade do Porto. Investigadora Sénior do Instituto de Sociologia da Universidade do Porto, do Griffith Center for Social and Cultural Research na Austrália, do Centro Investigadora do Centro de Estudos de Geografia e do Ordenamento do Território (CEGOT), do Centro de Investigação Transdisciplinar «Cultura, Espaço e Memória») (CITCEM) e do Centro de Estudos sobre a Mudança Socioeconómica e o Território (DINÂMIA'CET-IUL). ORCID: http://orcid.org/0000-0003-2377-8045. E-mail: <pguerra@letras.up.pt>, <paula.kismif@gmail.com>.
} 
O que tem o rock a ver com Bourdieu?

involved in the production and publication spheres of the Portuguese alternative rock segment.

Keywords: Cultural production. Alternative rock. Pop Rock. Social Field. Bourdieu. Portugal. 


\section{Prelúdio à fórmula informadora do rock alternativo}

O amor da arte, como o amor, mesmo e sobretudo o mais louco, sente-se fundado no seu objecto. É para se convencer de ter razão em (ou razões de) amar que recorre com tanta frequência ao comentário, essa espécie de discurso apologético que o crente dirige a si próprio e que, além de ter pelo menos como efeito redobrar a sua própria crença, pode ainda despertar e convocar os outros para a mesma crença. É por isso que a análise científica, quando é capaz de trazer à luz do dia aquilo que torna a obra de arte necessária, ou seja, a fórmula informadora, o princípio gerador, a razão de ser, fornece d̀ experiência artística, e ao prazer que a acompanha, a sua melhor justificação, o seu alimento mais rico (Bourdieu, 1996:17).

Falar em rock alternativo ${ }^{2}$ em Portugal implica referir um conjunto de posições num espaço social específico situado no universo pop rock e simultaneamente localizado nos contextos estruturais do campo artístico português e, consequentemente, do seu espaço social. Assim, podemos hipoteticamente supor que a música como prática e consumo está relacionada ao funcionamento complexo das estruturas sociais; como tal, a criação, disseminação ou consumo de música depende de instâncias criativas, sujeitas a imperativos culturais, económicos, sociais ou simbólicos relevantes (XXX, 2010, 2013, 2016). Neste artigo $^{3}$ discutimos as representações sociais sustentadas pelos agentes que participam da cena do rock alternativo em diferentes papéis (músicos, promotores, editores, bloggers, entre outros); representações essas que derivam simultaneamente do lugar ocupado pelos atores na cena do rock alternativo e da posição que ocupam na estrutura social geral (HIBBETT, 2005). O nosso objetivo principal é identificar as autorrepresentações de criadores/produtores de rock alternativo em Portugal e considerar os papéis dinâmicos e posições simbólicas desempenhados pelos agentes envolvidos, servindo-nos para iluminar este objeto da teoria dos campos de Bourdieu. Também abordamos as particularidades dessas representações na

\footnotetext{
2 Vale ressaltar que, a partir da década de 1980, a expressão "rock alternativo" foi reificada em Portugal, referindo-se a atores, promotores, bandas, selos, programas de rádio e cenas específicas em Lisboa e Porto e, embora menos representativamente, em Coimbra e Braga. Aglomerada todo um conjunto de cultores do pós-punk e afins. O rock alternativo começou a adquirir materialidade e linguagem específicas, articulando um campo de posições sociais e lógicas do mundo da arte, mas também correspondendo a um espaço de encontro experimental, como uma cena que se alimenta de território, de territórios.

3 Este artigo decorre do desenvolvimento do projeto de doutoramento da autora intitulado "Culturas urbanas e modos de vida juvenis: cenários, sonoridades e estéticas na contemporaneidade portuguesa (2005 - 2009)" (referência SFRH/BD/24614/2005) no âmbito do Instituto de Sociologia da Universidade do Porto (IS - UP) e da Fundação de Ciência e Tecnologia (FCT). O desenvolvimento deste projeto deu origem à tese de doutoramento referenciada aqui como XXX (2010).
}

CSOnline - Revista Eletrônica de Ciências Sociais, Juiz de Fora, n. 32 (2020). 
sociedade portuguesa nos últimos 30 anos e o desafio sociológico que ela implica, reconhecendo que a adoção de géneros musicais em territórios históricos e sociais particulares é altamente complexa e incorpora padrões de reprodução, mas também de inovação (REGEV, 2007; STANKOVIC, 2001; SZEMERE, 2001).

Os dados apresentados e discutidos são o resultado de uma pesquisa de longo prazo realizada entre 2005 e 20104. Foram realizadas entrevistas semiestruturadas e biográficas com 202 indivíduos (envolvidos nas esferas de produção e publicação do segmento de rock alternativo português), seguindo a técnica de amostragem "bola de neve". O objeto analítico foi estabelecido por meio de contatos fornecidos pelos entrevistados, o que deu à investigação ampla cobertura em termos de género musical, de território e de agentes sociais envolvidos. A nossa metodologia foi orientada pela análise de conteúdo dos segmentos discursivos, a fim de verificar os significados e finalidades das ações sociais, privilegiando, portanto, abordagens qualitativas e intensivas. Com o objetivo de ilustrar a estrutura hierárquica do rock alternativo em Portugal (relativamente às formas de os indivíduos se relacionarem e se associarem), apresentam-se também os principais resultados de uma análise baseada em redes fundadas numa dinâmica poliédrica5.

A amostra foi composta por conjuntos de indivíduos classificados da seguinte forma: 55 entrevistados entre 36 e 40 anos, 33 entrevistados entre 31 e 35 anos e 35 entrevistados entre 41 e 45 anos. Predominantemente masculina, a amostra reflete lógicas de género geralmente presentes no rock, principalmente entre as gerações mais velhas no contexto português. O grupo também apresentou alto nível educacional (85 graduados e 54 com

\footnotetext{
4 Foram realizadas cento e noventa e uma entrevistas semiestruturadas com os vários agentes presentes no campo de análise, complementadas por 11 entrevistas biográficas com atores marcantes, de charneira (diacrónica e sincronamente) do rock alternativo portugueses. Realizadas entre agosto de 2006 e fevereiro de 2009, as entrevistas cobriram a diversidade de agentes no subcampo: bloggers, críticos e jornalistas, promotores, editores, gerentes, proprietários de locais de distribuição de música, lojistas, músicos, DJs e amantes da música (basicamente, apenas agentes vistos como audiência foram excluídos). Todas as entrevistas foram gravadas em áudio digital e juntas compõem um tempo total de reprodução de aproximadamente 300 horas.

5 Se etimologicamente, a palavra poliedro deriva dos termos gregos poli (muitos) e hedro (plano), para o que aqui nos interessa, o conceito assenta numa abordagem pluridimensional baseada em várias estruturas de ligações apontadas por um conjunto de indivíduos. Estas estruturas de ligações entre os elementos identificados pelos indivíduos entrevistados foram realizadas com base nas matrizes de frequências de referências comuns (Quadros de Burt dos elementos de cada categoria). A representação das relações entre elementos teve como suporte teórico o método designado como dinâmica de poliedros. Dinâmica de Poliedros ou "linguagem de estrutura" é uma linguagem matemática desenvolvida com o objetivo de descrever e discutir questões estruturais. Esta linguagem é descrita em topologia algébrica.
} 
frequência universitária). As posições sociais altamente colocadas dos participantes parecem congruentes com as suas qualificações académicas, profissionais e sociais, que contrastam claramente com o perfil médio da população portuguesa, mas que estão intimamente relacionadas com o perfil típico dos grupos artísticos. A maioria da nossa amostra veio das áreas metropolitanas de Lisboa (75\%) e Porto. A amostra é distribuída geograficamente de acordo com a distribuição espacial dos membros do campo artístico em geral, refletindo as dualidades e assimetrias culturais (se não a macrocefalia) do país.

\section{O rock alternativo como espaço social relacional ou interrogando a instável matéria da música}

Seguindo uma linha de pensamento relacional, recuperamos a origem do conceito de campo, tarefa que requer uma análise contextualizada da teoria bourdieusiana (REGEV, 2007). A sociologia não deifica mecanismos: os campos sociais são campos de forças, mas também são campos de lutas para transformar ou preservar esses mecanismos. Para Pierre Bourdieu, a noção de campo representa um espaço social de dominação e conflito, onde cada campo possui relativa autonomia e as suas próprias regras de organização e de hierarquia social (BOURDIEU \& WACQUANT, 1992, p. 24). Bourdieu define espaço social como um conjunto organizado ou sistema de posições sociais que são definidas umas em relação às outras. É um todo cujas partes componentes estão em interação umas com as outras de forma durável e não arbitrária. Cada parte só toma significado na relação com as outras, ou seja, a tomada de posição social só ganha sentido na e pela diferenciação.

Cada campo está por sua vez estruturado segundo "posições dominantes" e "posições dominadas", determinando os "lugares" dos agentes que nele intervêm, que se materializam num espaço de luta com vista à conquista de posições dominantes. Cada campo está ligado aos outros campos por ligações económicas e simbólicas, mas possui uma certa "autonomia", que se traduz, entre outros aspetos, por "interesses" específicos no campo. O que se produz e o que se troca nos campos não são apenas recursos raros como riqueza material, prestígio ou poder, mas também significado, que atribui uma identidade social aos agentes, distinguindo-os uns dos outros. Os agentes ocupam diferentes "posições" segundo os campos, que remetem para as "disposições" herdadas ou adquiridas ao longo da vida. Assiste-se a "estratégias de 
conservação" e de conquista de posições dominantes. No plano simbólico, as estratégias de conservação esforçam-se por manter a norma comum, que evita pôr em causa as posições. As "estratégias de subversão" têm por finalidade desvalorizar a normas dominantes bem como o capital que the está associado. Ter presente o carácter objetivo do campo de produção cultural implica conceber o seu modo de funcionamento como análogo ao de um campo magnético, perspetivando o carácter objetivo de relações entre cada agente e a sua obra, entre o criador e o seu público, mediatizadas pela ação dos difusores e dos críticos (todos agentes interatuantes deste campo). Este campo é pautado por uma autonomia de funcionamento relativa e, portanto, uma "lógica original". A construção do mundo social é inseparável das representações (re)produzidas continuamente pelos agentes, no tempo e no espaço; é nesta (re)produção contínua de representações que encontramos a génese e o contorno (sempre instáveis) do rock alternativo em Portugal.

\section{Genealogia do rock alternativo}

O campo do pop rock em Portugal foi sendo constituído ao longo dos anos 60 e 70 do século passado pela crescente capacitação de agentes e estruturas de funcionamento do campo, designadamente estúdios de gravação, editoras, jornais e revistas, programas de rádio, artistas e bandas, locais de realização de espetáculos, etc. O início dos anos 80 do século XX marcou o boom do rock português, ocorrendo aí toda uma série de transformações em prol da concretização e viabilização desta indústria cultural. A indústria da música pop rock configurou-se então numa constelação complexa de editoras, órgãos de comunicação social, produtos (discos, cassetes, revistas, jornais, posters) e agentes sociais (músicos, produtores, jornalistas, críticos, radialistas, disc jokeys, lojistas...), com diversas especificidades e em menor escala, naturalmente, do que acontecia noutros países, mas ainda assim à imagem do que internacionalmente se ia verificando, especialmente nos EUA. Os anos 80 trouxeram a vulgarização das obras (discos e hits) e, dessa forma, a relevação, de forma mais clara do que outrora, de que as bandas e artistas não se encontram isolados do mundo, mas que, muito pelo contrário, as suas produções detêm um elevado grau de relacionamento com a memória coletiva e a memória da música. Também a imagem do artista enquanto "rebelde" e distante das massas foi, em grande 
medida, quebrada nesta altura. Dinâmicas sociais e dinâmicas artísticas convergem: primeiro a revolução democrática de 25 de Abril de 1974 e a progressiva abertura da sociedade portuguesa ao exterior, depois a entrada na Comunidade Económica Europeia, a inovação tecnológica e a maior acessibilidade aos instrumentos e equipamentos, um mercado discográfico em crescimento, um maior interesse por parte da televisão e da rádio, meios de comunicação social também eles em mudança, a circulação internacional de valores, ideias e imagens, tudo contribuiu para consolidar o campo do pop rock em Portugal.

O facto de a música pop rock ser, em si mesma, um produto que, como tantos outros, pode ser comprado e vendido e dar lucro mostrou, de forma evidente, através do negócio que se montou e que rapidamente cresceu, a sua imbricação e importância face à sociedade em geral e integrou-o numa estrutura muito mais ampla de outros negócios. Aqui se encontra, de resto, uma das tensões que mais influência têm na dinâmica do campo do rock - e, em especial, do segmento dito alternativo: apresentando-se como estilo de vida libertador de amarras e de constrangimentos societais, ele é também negócio, expoente determinante da economia da cultura. A partir de 1986, esta tensão evidencia-se com a ocorrência de diversas movimentações tendentes à constituição de um subcampo do rock alternativo dentro do campo geral do pop rock em Portugal. A existência de agentes e estruturas em confronto e oposição ao establishment, aos seus valores e missão, está na génese deste subcampo. A abertura do país ao exterior, o reforço do processo de urbanização, a entrada em cena de uma certa 'movida' (cenas lúdicas, artísticas, culturais e de moda) pós-moderna nas cidades de Lisboa e, em menor intensidade, no Porto, fenómenos contemporâneos do surgimento de bandas (Mão Morta6, Pop Dell'Arte7, Mler If Dada', etc.), editoras

\footnotetext{
6 Banda de rock portuguesa, criada em 1984, na cidade de Braga. O seu som apela a um rock agressivo, com especial ênfase nas palavras.

7 São uma banda de música portuguesa, que teve o seu início na década de 1980 e que, ainda hoje, se mantém ativa. Ao longo do tempo, inúmeros músicos de renome já atuaram em conjunto com os Pop Dell'Arte.

8 Trata-se de uma banda portuguesa, formada em Cascais em 1984. O surgimento desta banda teve como mote duas sessões de improviso tendo daí nascido os temas "Zimpó" e "Nu ar". Mais tarde acabam por vencer o Concurso de Música Moderna do Rock Rendez-Vous.
} 
(Ama Romanta99, Fundação Atlântica10, Facadas na Noite11, etc.), fanzines, programas de rádio (Som da Frente por exemplo), referências e locais de divulgação e fruição, marcam o contexto de emergência deste segmento do campo, em confronto com os princípios de massificação do pop rock em geral. As repercussões das suas atividades e tomadas de posição far-se-ão sentir no espaço e no tempo até ao presente.

A emergência, e progressiva sedimentação, do subcampo do rock alternativo em Portugal, passou pela criação de segmentos e nichos específicos de público, pela emergência de produtores e criadores especializados, pela sedimentação de instâncias de consagração e de legitimação e, mais importante, pelo facto de existir a partir desta altura um corpo de obras implícita ou explicitamente dirigido ao subcampo e refletindo a sua história. Porventura, o exemplo mais cabal situa-se na estratégia de atuação de determinadas bandas, de onde destacaremos os Mão Morta, na medida em que os seus membros não se ocupam do projeto a tempo inteiro, nem de forma profissional, sendo essa uma atitude deliberada de posicionamento, acompanhada por uma declaração face à emoção pela música em si. Também os Pop Dell'Arte, pela sua enunciação recorrente de instâncias de legitimação ou pela alusão a uma espécie de comunidade artística e estética, parecem evidenciar sobejamente estes posicionamentos. Ouçamos Adolfo Luxúria Canibal, vocalista e líder dos Mão Morta:

Em Portugal, como mercado pequeno que é, acho que é complicado viver da música. Seja como for, foi uma coisa que nunca esteve nos nossos objetivos, nem nos nossos horizontes, nem para mim nem para nenhum de nós, Mão Morta, viver da música. Mesmo nos momentos de maior público, tipo Mutantes S21, etc., sempre recusámos essa possibilidade. Quando eu digo recusámos, quero dizer que nem sequer a colocámos. (Adolfo, História de Vida 2, 50 anos, Mestrado, Braga)

\footnotetext{
9 Ama Romanta era a designação da editora de João Peste - vocalista dos Pop Dell'Arte - e na segunda metade dos anos 1980 era vista como a alternativa dentro do campo musical português, tendo sido criada com o objetivo de lutar contra a censura das rádios e das editoras da época.

10 Fundação Atlântica foi uma editora discográfica independente portuguesa, fundada em 1982. Esta editora foi responsável pela produção dos discos das bandas portuguesa mais emblemáticas, tais como os Sétima Legião, Xutos e Pontapés ou os Delfins.

11 Facadas na Noite é uma editora portuguesa, relacionada com a música eletrónica, industrial e experimental, que nasceu em 1988 na cidade de Braga pelas mãos de Jorge Pereira.
} 


\section{Leis gerais do subcampo do rock alternativo}

De acordo com Bourdieu, é possível falar em "leis gerais dos campos": campos tão diferentes como os da política, da religião ou da música têm "leis de funcionamento" que são, em grande medida, transferíveis, o que possibilita que o que se aprende com o estudo de um dado campo possa ser utilizado para interrogar ou interpretar outros campos. Por outro lado, este facto não inviabiliza que se procurem e descubram, para além dos mecanismos universais dos campos, propriedades específicas, próprias de um campo em particular. Não obstante, sabemos que em todos os campos encontramos uma luta, cuja forma específica deveremos interrogar: "de facto, as revoluções parciais que nos campos continuamente têm lugar não põem em questão o fundamento do próprio jogo, a sua axiomática fundamental, o alicerce de crenças últimas sobre as quais assenta todo o jogo" (BOURDIEU, 2004, p.122). Um campo define-se, entre outras coisas, pelo(s) seu(s) enjeu(x) (as paradas em jogo), que são irredutíveis aos enjeux e interesses específicos próprios de outros campos e que não são percebidos senão por quem estiver preparado para os intuir e prosseguir: "para que um campo funcione, é preciso que nele haja enjeux e pessoas preparadas a jogar o jogo dotadas do habitus imbuído do conhecimento e reconhecimento das leis imanentes do jogo, dos enjeux, etc." (BOURDIEU, 2004, p. 120). A estrutura do campo é um estado da relação de forças entre os agentes ou as instituições envolvidas na luta ${ }^{12}$ ou, se se preferir, da distribuição de capital específico que, acumulado ao longo das lutas anteriores, orienta as estratégias ulteriores:

os campos apresentam-se à apreensão sincrónica como espaços estruturados de posições (ou de postos), cujas propriedades dependem da sua posição nesses espaços e que podem ser analisadas independentemente das características dos seus ocupantes (em parte determinadas por elas) (BOURDIEU, 2004, p. 119).

\footnotetext{
12 Bourdieu refere: "Não basta dizer que a história do campo é a história da luta pelo monopólio da imposição das categorias de percepção e de apreciação legítimas; é a própria luta que faz a história do campo; é por meio da luta que o campo se temporaliza. O envelhecimento dos autores, das obras ou das escolas é uma coisa completamente diferente do produto de um deslizar mecânico em direcção ao passado: engendra-se no combate entre aqueles que fizeram época e que lutam por durar, e aqueles que não podem por seu turno fazer época sem remeterem para o passado os que estão interessados em deter o tempo, em eternizar o estado presente; entre os dominantes que se ligam à continuidade, à identidade, à reprodução, e os dominados, os que entram em cena no momento actual, interessados na descontinuidade, na ruptura, na diferença, na revolução. Fazer época é inseparavelmente fazer existir uma nova posição para lá das posições estabelecidas, adiante dessas posições, na vanguarda, e por isso é também, introduzindo a diferença, produzir o tempo" (BOURDIEU, 1996, p. 186).
}

CSOnline - Revista Eletrônica de Ciências Sociais, Juiz de Fora, n. 32 (2020). 
A estrutura dos campos está, ela própria, sempre em jogo: as lutas que ocorrem num campo têm por enjeux o monopólio da violência legítima (autoridade específica) que é característica do campo considerado, quer dizer, em definitivo, a conservação ou subversão da estrutura da distribuição do capital específico. O capital vale em relação com determinado campo, logo dentro dos limites desse campo, e não é convertível noutra espécie de capital senão sob certas condições: "falar de capital específico é dizer que o capital vale em relação com um certo comportamento, nos limites desse campo, ou que não é convertível numa outra espécie de capital a não ser em certas condições" (BOURDIEU, 2004, p. 121).

Assim, é fundamental determo-nos na autorrepresentação dos músicos, dos promotores de eventos, dos jornalistas e críticos, dos managers, dos editores e dos bloggers acerca do subcampo em que operam. Há, claramente, um autorreconhecimento de que se trata de um campo muito conflitual, trespassado por lógicas hierárquicas de poder e de luta. Concomitantemente, este carácter hierárquico é acentuado pela perceção de que o campo da música funciona amplamente em virtude de "conhecimentos" e "relações" muito interpessoais, de "simpatias" e de "troca de favores". Aliás, a própria proximidade entre os diversos agentes do campo acaba por se tornar um constrangimento relacional na tomada de decisões. Daí que considerado um espaço relacional de conflitualidade alargada, é possível considerar as dificuldades de implantação das pequenas bandas, dotadas de menores recursos culturais e simbólicos e a capacidade de imposição de agentes, que não sendo músicos, têm nas suas mãos o "poder". Beatriz, uma das músicas entrevistadas, refere:

\begin{abstract}
Portugal é muito pequeno e é gerido por muito poucas pessoas que fazem aquilo que querem. Por exemplo, existe uma certa forma de pensar assente no seguinte: 'nós estamos a fazer-vos um favor em estar a deixar-vos a tocar neste festival'. É por isso que os pais não gostam que os filhos tenham bandas. Esta mentalidade é generalizada a todo o tipo de arte, à exceção da arquitetura. É a tal questão de se ver a arte como um Iuxo. As pessoas não dão valor quando veem uma banda pequena. É mais fácil chegar ao topo porque o meio é pequeno. Controlando as redes, consegues. (Beatriz, Músico 33, 29 anos, Licenciatura, Lisboa)
\end{abstract}

A lógica de mercado, contra a qual, em grande medida, este subcampo do rock alternativo afirma ter-se constituído, tem vindo, entretanto, a entrar nele com cada vez mais força, introduzindo novas divisões e hierarquias, formas de distanciamento ou 
denegação face às "influências" e lobbies que o atravessam. A representação da conflitualidade ínsita a este subcampo também é relacionada, para alguns entrevistados, com a inexistência de uma indústria musical nacional capaz de se estruturar e defender as obras e apresentações das bandas. Com a consolidação do rock alternativo, através da presença de mais agentes, da criação de um corpo de estabelecidos dentro do alternativo, da ampliação dos públicos, do relativo sucesso comercial (de alguns protagonistas), vai-se alterando o papel deste segmento no interior do campo mais vasto do pop rock. Assim, o subcampo emergente vai ter um papel de charneira. Papel corporizado, por um lado, no seu pendor alternativo, crítico, novo (reação e subversão heterodoxa face aos "dominantes"/"comerciais"/"maus artistas") e por outro lado, face a um grupo considerável de recém-entrados ou de protagonistas que pretendem aceder ao campo13; Por isso, Bourdieu diz-nos que:

os autores consagrados que dominam o campo de produção tendem a impor-se também pouco a pouco no mercado, tornandose cada vez mais legíveis e aceitáveis à medida que se banalizam através de um processo mais ou menos longo de familiarização associado ou não a uma aprendizagem específica. As estratégias dirigidas contra a sua dominação visam e atingem sempre, através deles, os consumidores distintos dos seus produtos distintivos (BOURDIEU, 1996, p. 189).

\section{Determinantes e propriedades do rock alternativo português}

De que forma "solucionam" os protagonistas a sua inserção dúplice no campo (olham "para cima", criticando os artistas "comerciais" ou os "não artistas" do campo, mas, ao mesmo tempo, funcionam como gatekeepers para os que a ele pretendem aceder por via do segmento que dominam)? Através de uma reconstituição permanente de fronteiras, com vista a sublinhar a conservação de uma "cena alternativa" e a sedimentação da sua legitimação e círculo de crença pela montagem de um circuito alternativo e pela repetição nos canais mediáticos de nomes. Poderemos estar perante agentes calculadores e estratégicos, no qual somos

\footnotetext{
13 Assim, "os recém-chegados não podem deixar de remeter continuamente para o passado, no mesmo movimento através do qual acedem à existência, quer dizer, à diferença legítima ou até, por um tempo mais ou menos longo, à legitimidade exclusiva, os produtores consagrados com os quais se medem e, por conseguinte, os seus produtos e o gosto daqueles que Ihes permanecem ligados. É assim que as galerias ou as editoras, como os pintores ou os escritores, se distribuem a cada momento segundo a sua idade artística, isto é, segundo a antiguidade do seu modo de produção artístico e segundo o grau de canonização e de divulgação desse esquema gerador que é ao mesmo tempo esquema de percepção e de apreciação" (BOURDIEU, 1996, p. 187).
}

CSOnline - Revista Eletrônica de Ciências Sociais, Juiz de Fora, n. 32 (2020). 
incitados a considerar que a maior parte dos agentes age num espírito de racionalidade: confrontados com um universo incerto, eles procuram reduzir as incertezas, produzindo normas ou apoiando-se sobre convenções (BÉRA \& LAMY, 2003, p. 152). Aqui, poderemos sempre equacionar se o apelo ao "amor pela arte" não será acompanhado do cálculo da arte como um meio como nos adianta Xavier:

\begin{abstract}
Talvez na música mainstream haja essa questão das vendas que cai nessas disputas, mas ao nível destes artistas menos conhecidos, não há muito isso. Acho até que grande parte deles se conhece e querem é que toda a gente tenha sucesso e ficam contentes com o sucesso dos outros. Acho que não há assim muitas invejas, porque não há grande retorno financeiro. Acho que não se vê assim grandes problemas no meio de nichos mais especificos, que é o que conheço melhor. Não sei o que se passa a outra dimensão e com outros intervenientes. (Xavier, Jornalista 18, 29 anos, Licenciatura, Lisboa)
\end{abstract}

Quem, num determinado estado das relações de força, monopoliza (mais ou menos completamente) o capital específico, tende a prosseguir estratégias de conservação (no caso dos campos onde se produzem bens culturais, tendem à defesa da ortodoxia); pelo contrário, os agentes menos providos de capital (geralmente os que mais recentemente chegaram ao campo e, por isso, muitas vezes, os mais jovens) tendem a prosseguir estratégias de subversão (heresia/heterodoxia):

é a heresia, a ortodoxia, como ruptura crítica, frequentemente ligada à crise, com a doxa, que faz sair os dominantes do silêncio e que os impele a produzir o discurso defensivo da ortodoxia, pensamento direito e de direita destinado a restaurar o equivalente da adesão silenciosa da doxa (BOURDIEU, 2004, p. 121).

No interior do próprio campo, as lutas são fundamentais e as posições de dominação destacam-se. Desde logo, a reduzida dimensão do campo, torna-o um campo de interconhecimento pessoalizado muito relevante, sendo essa desde logo a primeira certeza do seu funcionamento hierárquico e conflitual. Quando questionados acerca dos agentes determinantes do campo e das próprias determinantes do subcampo, os agentes em situação, por nós abordados, destacam primeiramente o papel da crítica e do jornalismo, não obstante reiterarem a sua perda de importância relativa face à emergência de novos canais e fontes de informação, designadamente provenientes da Internet, na figura dos blogues. De forma semelhante, também é dada importância 
de relevo ao segmento dos managers e do agenciamento, pois são estes agentes que detêm o poder de dar visibilidade e rentabilidade aos diferentes projetos. A par, surgem também referências aos lobbies importantes para a sedimentação da carreira dos músicos associados às rádios ou a alguma imprensa. Seguidamente, e por ordem decrescente de importância, são referenciadas as promotoras de eventos, pois nelas residem as opções concretas de apresentação ao vivo dos projetos. A par, destacam-se os opinion makers, isto é, agentes que, pela sua trajetória no campo (sejam músicos, jornalistas, radialistas ou editores), adquiriram relevância em termos de personalidades de referência para a própria canonização do campo. De forma menos pontuada surgem as editoras, os projetos musicais consolidados, os próprios músicos, as distribuidoras, os responsáveis por espaços de divulgação, a TV, os públicos e as lojas de música.

Os jornalistas sempre foram muito importantes, os jornalistas, não os jornais, sempre foram muito importantes para a divulgação da música, estrangeira e portuguesa no que nos diz respeito. (Francisco, Músico 16, Músico, 36 anos, Mestrado, Porto)

Tudo o que se passa na indústria discográfica em Portugal passa-se nos bastidores. Tu vais a concertos e não há os chamados AgR das editoras que vão assinar as bandas. As coisas não se passam assim em Portugal. Em Portugal tu conheces alguém que conhece alguém que conhece essa pessoa e muitas vezes ele ou ela vão ver um ensaio. (Diogo, Músico 19, 36 anos, Músico, Licenciatura, Matosinhos)

Dado curioso é o de que as referências são na generalidade hetero-referências: assim a nomeação nunca incide nos próprios, mas sempre num outro; assim, é um "outro" que tende a preencher a discursividade inerente à enunciação dos dominantes, camuflando a disputa pela "parada em jogo", como, de resto, Bourdieu constatou que os agentes são

aparentemente implacáveis, salvaguardam o essencial: a convicção que os protagonistas neles investem. A participação nos interesses constitutivos da pertença ao campo (que os pressupõe e os produz através do seu próprio funcionamento) implica a aceitação de um conjunto de pressupostos e de postulados que, sendo a condição indiscutida das discussões, são, por definição, mantidos ao abrigo da discussão (BOURDIEU, 1996, p. 198).

Reconhecendo-se a importância dos jornalistas ou dos agentes na estruturação deste subcampo, é possível reconhecer as debilidades

CSOnline - Revista Eletrônica de Ciências Sociais, Juiz de Fora, n. 32 (2020). 
destes agentes, nomeadamente dos jornalistas e críticos, pois encontram-se fortemente determinados por instâncias de legitimação internacional e têm um distanciamento importante face ao público em geral.

Os ditos críticos musicais portugueses seguem muito, agarram-se a uma espécie de Bíblia, que é a imprensa musical londrina, britânica e portanto tudo o que é capa de revistas e hype nas revistas londrinas, que muitas vezes é um fenómeno específico britânico, para consumo interno, é imediatamente importado para Portugal como sendo the next big thing e eu acho que é um exagero, porque aquilo normalmente são pastiche de coisas que já se fizeram ano passado, podem ser mais ou menos bem-feitas, mas não são propriamente novas, originais. (Miguel, Músico 46, 47 anos, Licenciatura, Porto)

Um segmento que nasce como heterodoxo, disruptivo e que visa pôr em causa o establishment, propõe independência face às lógicas de mercado massivas, reivindicando uma autonomia face aos valores do consumo imediato e uma diferença estética e artística perante a contínua descaracterização e massificação do pop rock. Os líderes e porta vozes do rock alternativo português opunham-se ao uso da arte para ganhar dinheiro, buscavam a pureza da forma que foram em tempos os ideais da vanguarda modernista (FOWLER, 1997, p. 76), assumindo a existência de uma cena alternativa importante e capaz de afrontar o status quo musical do pop rock vigente. Podemos fazer entrar a perspetiva de Menger (2002) que apresenta a vida do artista como uma "aposta" em termos de proveitos económicos e simbólicos, uma vez que compensa a fragilidade dos seus ganhos económicos pelo reconhecimento face ao meio, possibilitando uma conversão dos proveitos simbólicos em proveitos económicos.

Evidente que, se houvesse essa disponibilidade, se fosse um mercado normal, se fosse um mercado que não estivesse dependente do mainstream, de um gosto mainstream, se estivermos presos ao mercado nacional estamos dependentes de um gosto. Se não estivéssemos dependentes disso, se funcionássemos, ou se tivéssemos uma origem anglo-saxónica, se o nosso alvo fosse o mercado mundial, em que pudéssemos trabalhar nos pequenos segmentos de mercado à nossa vontade, somando esses mercados daria um mercado vastíssimo, a questão era outra. Não é uma questão de princípio, é uma questão de opção face à realidade. A questão nem sequer se coloca. É tão evidente que nem sequer é preciso pensar muito. (Adolfo, História de Vida 2, 50 anos, Mestrado, Braga)

CSOnline - Revista Eletrônica de Ciências Sociais, Juiz de Fora, n. 32 (2020). 
Outra propriedade fundamental de todos os campos subsiste numa cumplicidade objetiva subjacente a todos os antagonismos, já que todos os agentes envolvidos no campo têm um interesse fundamental na existência do campo. O campo implica crença, a crença de que o jogo vale a pena, de que vale a pena participar no jogo:

aqueles que participam na luta contribuem para a reprodução do jogo, ao contribuirem, mais ou menos completamente segundo o campo, para a produção da crença no valor das paradas em jogo. Os recém-chegados têm de pagar um direito de entrada que consiste no reconhecimento do valor do jogo la seleção e a cooptação concedem sempre muita atenção aos índices de adesão ao jogo, de investimento) e no conhecimento (prático) dos princípios de funcionamento do jogo (BOURDIEU, 2004, p. 122).

É a natureza dos conflitos em torno do poder que determina as competições no espaço social, especialmente através do estabelecimento dos parâmetros de posições dentro de vários campos - as regras da arte, as regras do mercado, etc. (FOWLER, 1997, p. 82). O efeito de campo acontece quando já não se consegue compreender uma obra (o seu valor) se não se conhecer a história do campo de produção da obra. A redução da obra à posição no espaço social do produtor ou do consumidor escamoteia tudo o que ela deve ao campo e à sua história. Neste sentido, poderemos mesmo enunciar os indícios de constituição de um campo: o primeiro deve-se à presença na obra de traços da relação objetiva (por vezes mesmo consciente) com as outras obras (passadas ou contemporâneas); o segundo liga-se à aparição de um corpo de conservadores das vidas (biógrafos) e das obras (especialistas, historiadores, etc.); o terceiro filia-se no reflexo da história do campo na obra e mesmo na vida do produtor.

Na abordagem do papel do jornalismo e da crítica e das suas relações com a configuração do rock alternativo em Portugal, é importante destacar algumas dimensões reflexivas apontadas pelos agentes sociais. A primeira salienta a diluição da importância do exercício da crítica no âmbito do jornalismo musical pela crescente proliferação da Internet e consequentemente de fóruns e de blogues que tendem a ocupar esse papel. A segunda manifestação associa a crítica musical a modalidades herméticas de funcionamento e de discursividade, encerrando um círculo onde só os próprios intervenientes são tidos em linha de conta, apontando o distanciamento da crítica face à população e alguns 
prenúncios de "arrogância" intelectual. A terceira tendência de posicionamento perspetiva a existência de um certo desinteresse e/ou desvalorização por parte da crítica musical em projetos nacionais, não contribuindo, tal como faz a imprensa internacional, para a mediatização e legitimação de determinadas cenas musicais. Em quarto lugar, e de forma paradoxal, é assumida a importância da crítica na criação de hypes e no despoletar de nichos musicais que depois crescem, pese embora estas valorizações dependerem sobremaneira da intensidade de redes sociais desenvolvidas no processo. Em quinto lugar, existe uma tendência de posicionamento que ressalva a diminuição do peso da rádio e dos programas de autor na divulgação de projetos alternativos, pese embora a importância de poucos exemplos localizados no Portugália 14 ou no Indiegente 15 . Por último, no quadro da discursividade analisada, não deixa de ser relevante a quase assunção de um paradoxo relativamente à crítica e ao jornalismo musical que oscila entre a crença na sua importância e a sua desvalorização enquanto suporte efetivo de divulgação de projetos musicais, pelas razões apontadas, mas também pela exiguidade do subcampo.

Há novo talento para ser ouvido, só não tem exposição suficiente. 0 novo talento não tem espaço porque as playlists respondem mais ao conhecimento do que ao reconhecimento. Há talento novo e há talento novo para ser escutado. O problema reside naquilo que se tornou numa característica da cultura portuguesa, a mesma cultura que, como qualquer outra, existe como um todo e não por partes, as pessoas têm preguiça para ouvir coisas novas, não são estimuladas. (Lucas, Promotora 11, 26 anos, Licenciatura, Lisboa)

Bourdieu reflete acerca do conceito de doxa, pois todos os campos se pautam por princípios não questionáveis, o que não equivale a dizer que as estratégias dos agentes envolvidos num dado campo são resultado de um cálculo cínico, da busca consciente de maximização do lucro específico, mas da relação inconsciente entre um habitus e um campo: "Max Weber dizia que os dominantes precisam sempre de uma "teodisseia dos seus privilégios", ou, melhor, de uma sociodisseia, quer dizer, de uma justificação teórica do facto de serem privilegiados" (BOURDIEU, 1989, p.53). Da mesma forma, os interesses em causa num

\footnotetext{
14 Programa de rádio realizado por Henrique Amaro na Antena 3 de divulgação da música lusófona nas suas componentes e bandas menos mainstream.

15 Programa de rádio realizado por Nuno Calado na Antena 3 há mais de 20 anos. O seu foco são as propostas alternativas de música a nível nacional e internacional.
} 
determinado campo não se vinculam a um mero utilitarismo, derivam dos investimentos dos agentes sociais nas diferentes apostas em jogo e na perspetiva de Bourdieu são condição e produto da vinculação a um determinado campo:

\begin{abstract}
quando as pessoas só têm que deixar correr o seu habitus para obedecerem à necessidade imanente do campo e satisfazer as exigências que nele se encontram inscritas (o que constitui em todo o campo a própria definição da excelência), não têm seja de que maneira for consciência de estar a sacrificar a um dever e menos ainda a buscar a maximização do ganho (especifico). Têm, portanto, - ganho suplementar de se verem e de serem vistas como perfeitamente desinteressadas (BOURDIEU, 2004, p. 126).
\end{abstract}

No caso em estudo, o que a multiplicidade de formas de apresentação e de representação do estatuto social do músico na atualidade que os discursos dos entrevistados apresenta - do músico como alguém glamourizado, ao músico como uma condição social transitória e precária, ao músico como um cidadão comum, ao músico como alguém que adotou um modo de vida sui generis, ao músico como sendo objeto de uma representação social estigmatizada no sentido de comportamentos e consumos desviantes e como tendo um estatuto social pouco reconhecido e valorizado -, o que esta multiplicidade tende a pôr em destaque é a ideia, precisamente, de que a "virtude" dos agentes está na possibilidade de "não estar dependente da música", ser "livre" dos constrangimentos impostos pela lógica de mercado e conseguir um "estatuto" independente do sucesso comercial alcançado. Uma das grandes convenções neste subcampo poderá ser a própria apologia de um exercício não convencional da atividade musical, reconhecendo-se que essa será a via possível de uma afirmação, pois as "regras" mudaram face ao que se passava em meados dos anos 80 do século XX, dada a diversidade de ofertas musicais existentes por via de um mundo mais globalizado e mais próximo.

Por isso, nada melhor do que fazer como os Mão Morta (...) porque não estão dependentes do seu sucesso comercial, para ter uma vida digna. Que é aquilo que muitas vezes falta aos músicos portugueses, ter uma vida digna. Há sempre aquela ideia da música ser hobby, não uma profissão. Há essa ideia pública em relação aos músicos. Importância/necessidade de exercer uma profissão para além da música, tendo em visa não depender dela para sobreviver - questão da independência/liberdade do músico para fazer o que quer. (Humberto, Jornalista 6, 38 anos, Licenciatura, Lisboa) 
$\mathrm{Na}$ sua abordagem da música enquanto resultado das convenções sociais, Martin (1995) refere a importância dos grupos dominantes na definição dessas convenções, nomeadamente dos críticos da música, que têm um forte papel no estabelecimento das mesmas, ou seja, no modo como a música deve ser produzida e ouvida. Inclusivamente, Martin apresenta o exemplo dos musicólogos como dotados de legitimidade para expressar juízos acerca da música acabando por formular uma hierarquia musical, característica das sociedades modernas. $\bigcirc$ processo de perpetuação das convenções sociais é então protagonizado por escritores, críticos e teóricos que definem as normas do seu "mundo artístico" (MARTIN, 1995, p. 184) e para assegurar a pertença a um determinado mundo artístico, nomeadamente ao mundo da música, os indivíduos deverão orientar a sua conduta de acordo com essas normas. A carreira de um músico dependerá, por assim dizer, da sua conformidade às convenções do campo artístico, à sua doxa, às suas crenças: "a existência de críticos pode constituir um indicador objetivo da dupla dimensão simbólica (prestígio) e económica (especulativa) dos bens e dos serviços culturais, o que impede a sua redução ao seu valor económico" (BERÁ \& LAMY, 2003, p. 155).

\section{Topos do rock alternativo português}

No tratamento das entrevistas realizadas, surgiu uma recorrência importante de palavras usadas pelos entrevistados para identificar os atores, locais, lojas, promotores e médias, que serviram de inspiração para a criação de um layout hierárquico com base no número de referências a essas mesmas palavras. As palavras usadas para identificar um determinado conjunto assumiram uma configuração hierárquica através da sua frequência de enunciação16. Dessa forma, foi possível identificar e criar uma topologia de posições que define o subcampo do rock alternativo em Portugal (relativamente às formas de os indivíduos se

16 foco do presente artigo prende-se com a compreensão da lógica subjacente e do funcionamento do segmento de rock alternativo português, no que diz respeito às representações dos indivíduos, numa perspetiva bourdieusiana. Para melhor compreender e visualizar essas conceções relacionais, desenvolveu-se uma análise baseada numa abordagem matemática chamada dinâmica poliédrica. Esse procedimento algébrico permitiu criar representações das estruturas de conexão entre os elementos identificados pelos entrevistados (bandas nacionais e internacionais, blogues, jornalistas, críticos, locais, lojas de discos e atores-chave da cena nacional do rock alternativo), concebidas com o uso de quadros de referências comuns, com o objetivo de descrever e discutir questões estruturantes na caracterização do rock alternativo. Um artigo publicado anteriormente (XXX, 2016) apresenta a análise realizada e é a origem das considerações apresentadas nesta secção.

CSOnline - Revista Eletrônica de Ciências Sociais, Juiz de Fora, n. 32 (2020). 
O que tem o rock a ver com Bourdieu?

relacionarem e se associarem), no que toca a três tipos de intervenientes relevantes: (1) as bandas; (2) as editoras, promotores de eventos e lojas de discos; (3) e os agentes-chave.

Figura 1: Dinâmica de poliedros aplicada à estrutura de ligações das bandas nacionais mais referenciadas pelos entrevistados (com um mínimo de 10 referências ou com referências em mais do que 1 função)

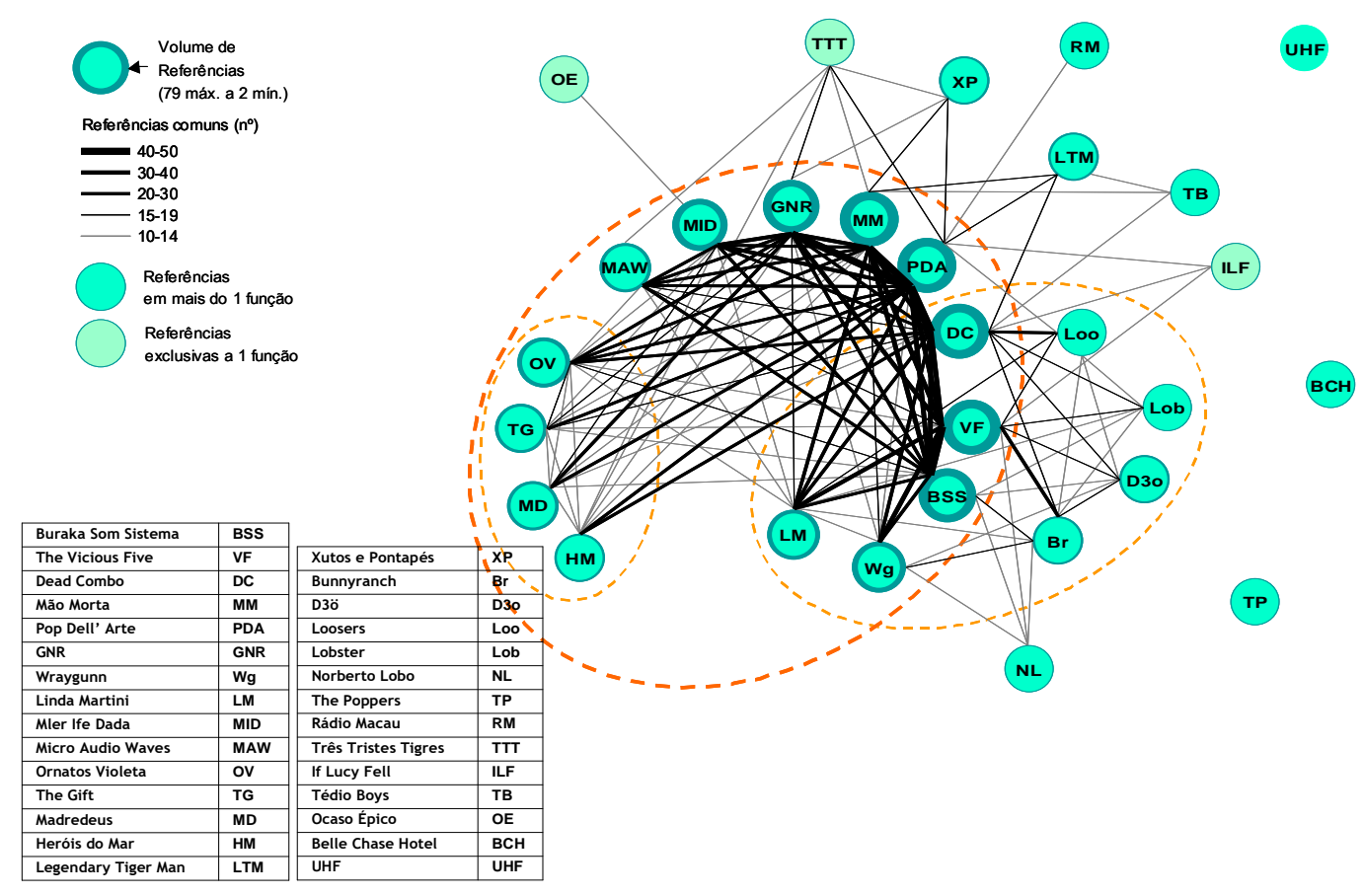

Fonte: Elaboração própria.

Relativamente às bandas, surge um primeiro grupo que parece estrutural na formação do rock alternativo português (Figura 1), constituído por bandas que são referidas por quase todos os entrevistados: Buraka Som Sistema17, The Vicious Five18, Dead Combo19, Mão Morta, Pop Dell'Arte, GNR20, Wraygunn'21, Linda

\footnotetext{
17 Banda portuguesa de kuduro, sendo a mesma considerada como um dos projetos musicais com maior projeção internacional, na década de 2000 e 2010.

18 Eram uma banda de rock oriunda de Lisboa, formada em 2003, em que diversos membros vinham do background do punk/Hardcore.

19 É uma banda portuguesa que possui influências musicais no campo do Fado e do Rock, bem como músicas da América do Sul e África. A banda apenas é constituída por dois elementos: Tó Trips e Pedro V. Gonçalves.

20 Também conhecidos como o Grupo Novo Rock, os GNR são uma banda portuguesa de pop rock, formada no Porto, na década de 1980.

21 Os Wraygunn é uma banda portuguesa originária de Coimbra. Eles ficaram conhecidos pela fusão de estilos vindos do Blues, Gospele sons de rock puro americano.
}

CSOnline - Revista Eletrônica de Ciências Sociais, Juiz de Fora, n. 32 (2020). 
Martini22, Mler Ife Dada, Micro Áudio Waves'23, Ornatos Violeta ${ }^{24}$, The Gift25, Madredeus ${ }^{26}$ e Heróis do Mar27 (por ordem decrescente de número de referências, referências estas em mais de um papel) (XXX, 2016). A maior parte destas bandas foi formada na segunda metade da década de 80 , profundamente influenciada pela estética pós-punk, e veio a assumir papel de "instituição de campo" devido à sua longevidade, protagonismo, liderança na definição dos cânones da criação artística, relacionamento independente com editoras e médias e proclamação contínua da ética do-it-yourself (DIY) - com seus membros a afastar a profissionalização das suas carreiras musicais. Essas "bandas veteranas" primárias são acompanhadas, por um segundo grupo, os "recém-chegados", que seguem uma lógica de exploração e experimentação sonora, evitam o envolvimento com grandes editoras e foram formadas por membros previamente integrados na formação das bandas consideradas instituições de campo. Podemos, de facto, referir-nos à existência de uma estrutura produtora de cânones de um subgénero musical (fundamentado no pós-punk, na experimentação musical e como ponte com a eletrónica) nas duas principais cidades de Portugal, Lisboa e Porto. Essa estrutura é caracterizada pela sua ética e lógica DIY, presença predominantemente amadora no que diz respeito à profissionalização, busca de uma alternativa às grandes editoras na criação de editoras independentes e pessoais - e uma reivindicação de uma esfera de ação cosmopolita à escala portuguesa (XXX, 2013). Este espectro de bandas está localizado nos principais arcos do rock alternativo das últimas três décadas em Portugal; as bandas ilustram claramente o que está por trás do "mundo alternativo" em Portugal, mesmo que esse alternativo seja plural e dinâmico, incluindo uma sonoridade e músicas híbridas, editoras independentes, concertos ao vivo, lógicas DIY, canonização por críticos e assim por diante.

\footnotetext{
22 'Banda portuguesa de rock conhecida pelas suas influências post-rock e punk, criados em 2003.

23 São um grupo musical português fundado em 2000 que começou por desenvolver composições minimalistas e experimentais.

24 São uma banda portuguesa de rock alternativo, com fusão de algumas tendências como o ska e o jazz, originários do Porto.

25 Os The Gift são uma banda portuguesa, de Alcobaça, formados em 1994. São uma banda conceituada que já ganhou o Globo de Ouro de Melhor Grupo.

26 Os Madredeus são um dos grupos musicais portugueses que possui maior projeção mundial. Estes são conhecidos por combinarem influências da música popular, do fado e da música erudita.

27 Os Heróis do Mar foram uma banda de pop-rock portuguesa, formada em 1981, em Lisboa.
} 
Figura 2: Dinâmica de poliedros aplicada à estrutura de ligações das editoras, promotoras de eventos e lojas de discos mais referenciadas pelos entrevistados (com um mínimo de 10 referências ou com referências em mais do que 1 função)

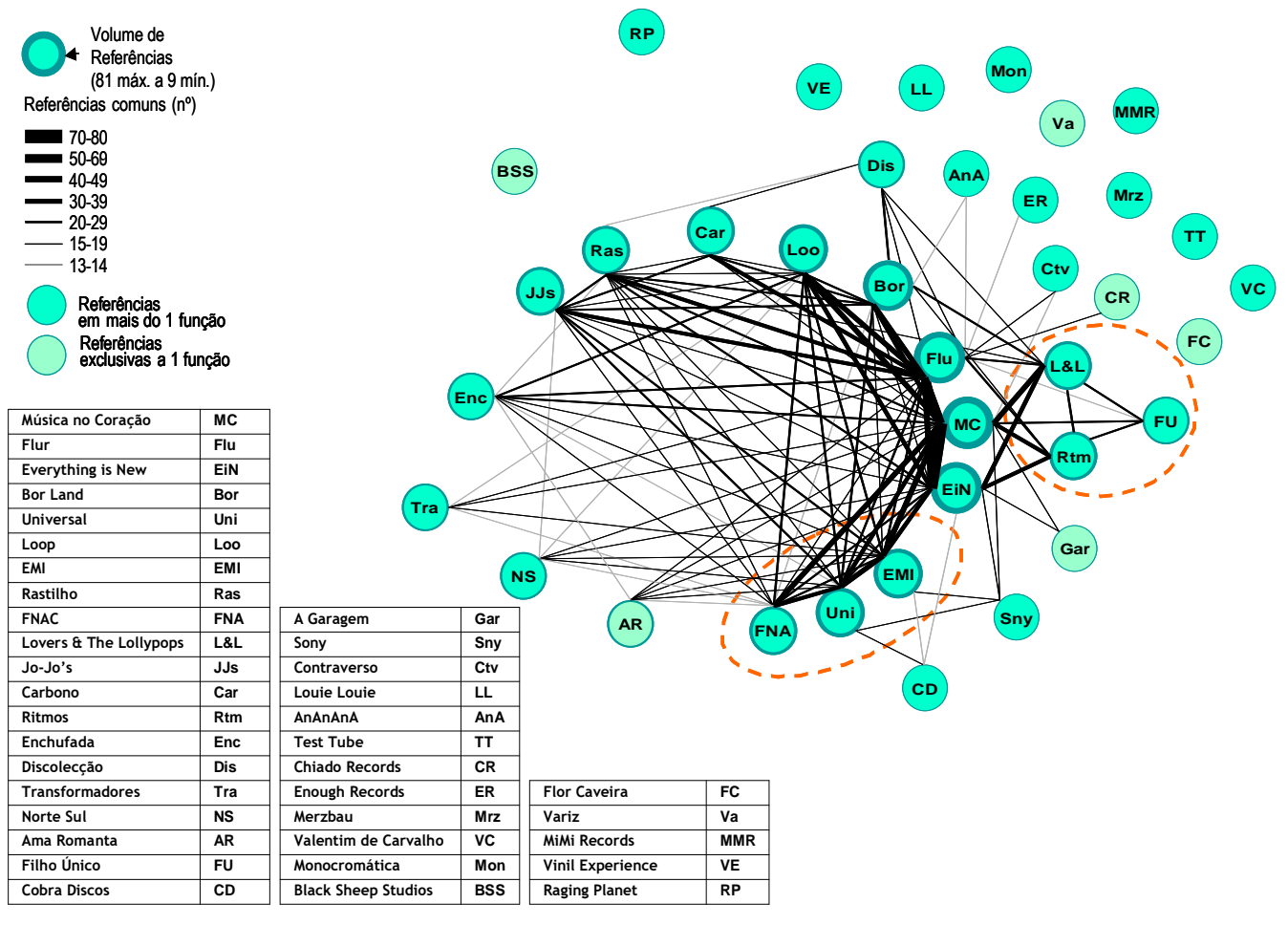

Fonte: Elaboração própria.

Quanto ao segmento de editoras, promotores de eventos e lojas de discos, é importante observar como uma estrutura é constituída em torno das posições de organizações alternativas e tradicionais (Figura 2): à primeira vista, os dados parecem conter algumas contradições. Citando apenas algumas das editoras/promotores mais referidos (por ordem de decrescente de número de referências, referências estas em mais de um papel) (XXX, 2016): Música no Coração28, Flur ${ }^{29}$, Everything is New30, Bor Land ${ }^{31}$,

28 Trata-se de mais antiga promotora de eventos pop rock nacional: a sua génese remonta a 1997. 29 Loja de discos fundada em 2001 em Lisboa. A Flur é sede de duas labels - a Holuzam (criada em 2018) e a Príncipe (que cofundou em 2011) - e tem projeção internacional. Entre várias possíveis expressões deste reconhecimento além-fronteiras estará o facto de ser a única loja de discos portuguesa representada no livro "Around The World In 80 Record Stores", de Marcus Barnes.

30 A Everything is New é uma promotora de eventos culturais, sediada em Lisboa e liderada por Álvaro Covões desde 2007

31 Editora fonográfica independente do Porto fundada em outubro de 2000 por Rodrigo Cardoso e Inês Lamares.

CSOnline - Revista Eletrônica de Ciências Sociais, Juiz de Fora, n. 32 (2020). 
Universal32, Loop 33 , EMl34, Rastilho 35 , FNAC 36, Lovers and The Lollypops ${ }^{37}$, Jo-Jo's ${ }^{38}$, Carbono ${ }^{39}$, Ritmos ${ }^{40}$, etc., é possível identificar um mix de entidades tradicionais e independentes. Apesar da crise associada ao mercado de discos, os promotores, as principais editoras e as independentes mantêm uma posição reconhecida e valorizada dentro da estrutura, baseada na importância de tais editoras e promotores na definição de "alternativo". No entanto, de uma forma fortemente ligada à socio-história portuguesa e à indústria da música (SZEMERE, 2001), um papel importante pode ser atribuído aos promotores que, hoje em dia, expandiram as suas atividades para além dos nichos alternativos (na tentativa de organizar alguns dos maiores eventos de Portugal), iniciando-se no final dos anos 80 e início dos anos 90 através de estratégias DIY, estruturas e funções organizacionais informais, alimentadas por um leitmotiv de procurar "a alternativa". No entanto, as suas atividades ramificaram-se gradualmente em expressões mais populares (mainstream), principalmente na criação de grandes eventos, como festivais (ver HIBBETT, 2005). Além disso, a evolução da indústria musical portuguesa é recente, levando algumas das editoras independentes do início dos anos 80 a adotarem uma postura mais mainstream e corporativa para com a produção musical. $O$ que parece evidente aqui é a coexistência aparentemente conflituosa entre micro e macro organizações e um ethos mainstream e alternativo: mas deve-se enfatizar que este é muito mais um conflito aparente do que real, um resultado da dinâmica geral da evolução dentro da indústria da música. Estes são os mais importantes princípios estruturantes deste subcampo do rock alternativo, que não escondem a dinâmica geral da luta dentro do segmento, nem impedem a oposição entre "reis do segmento" e "recém-chegados" (REGEV, 1994).

\footnotetext{
32 Uma das maiores editoras discográficas de Portugal.

33 A Loop:Recordings é uma editora portuguesa centrada no hip-hop fundada em 2001.

34 A EMI foi uma empresa multinacional britânica do ramo fonográfico com sede em Londres, Inglaterra. No momento da sua dissolução, em 2012, foi o quarto maior grupo de gravadoras da indústria musical e foi uma das quatro grandes majors fonográficas.

35 Editora fonográfica baseada em Leiria e que mantém atividade há mais de duas décadas.

36 Cadeia de lojas que opera no varejo/retalho, oferecendo produtos culturais e eletrónicos.

37 A Lovers \& Lollypops foi criada em 2005, numa lógica DIY. Até à data já editaram mais de 100 discos.

38 A Jo-Jo's Music foi fundada em 1978 no Porto e constituiu até ao seu encerramento em 2013 um marco nas lojas de discos independentes.

39 A Carbono abriu em 1993 em Lisboa e garante ser a primeira loja de discos usados em Portugal.

40 A Ritmos é uma das principais e mais prestigiadas produtoras nacionais de eventos em Portugal. São responsáveis pela organização de festivais como o Festival Paredes de Coura.
}

CSOnline - Revista Eletrônica de Ciências Sociais, Juiz de Fora, n. 32 (2020). 
Figura 3: Dinâmica de poliedros aplicada à estrutura de ligações dos agentes sociais mais referenciados pelos entrevistados (com um mínimo de 10 referências ou com referências em mais do que 1 função).

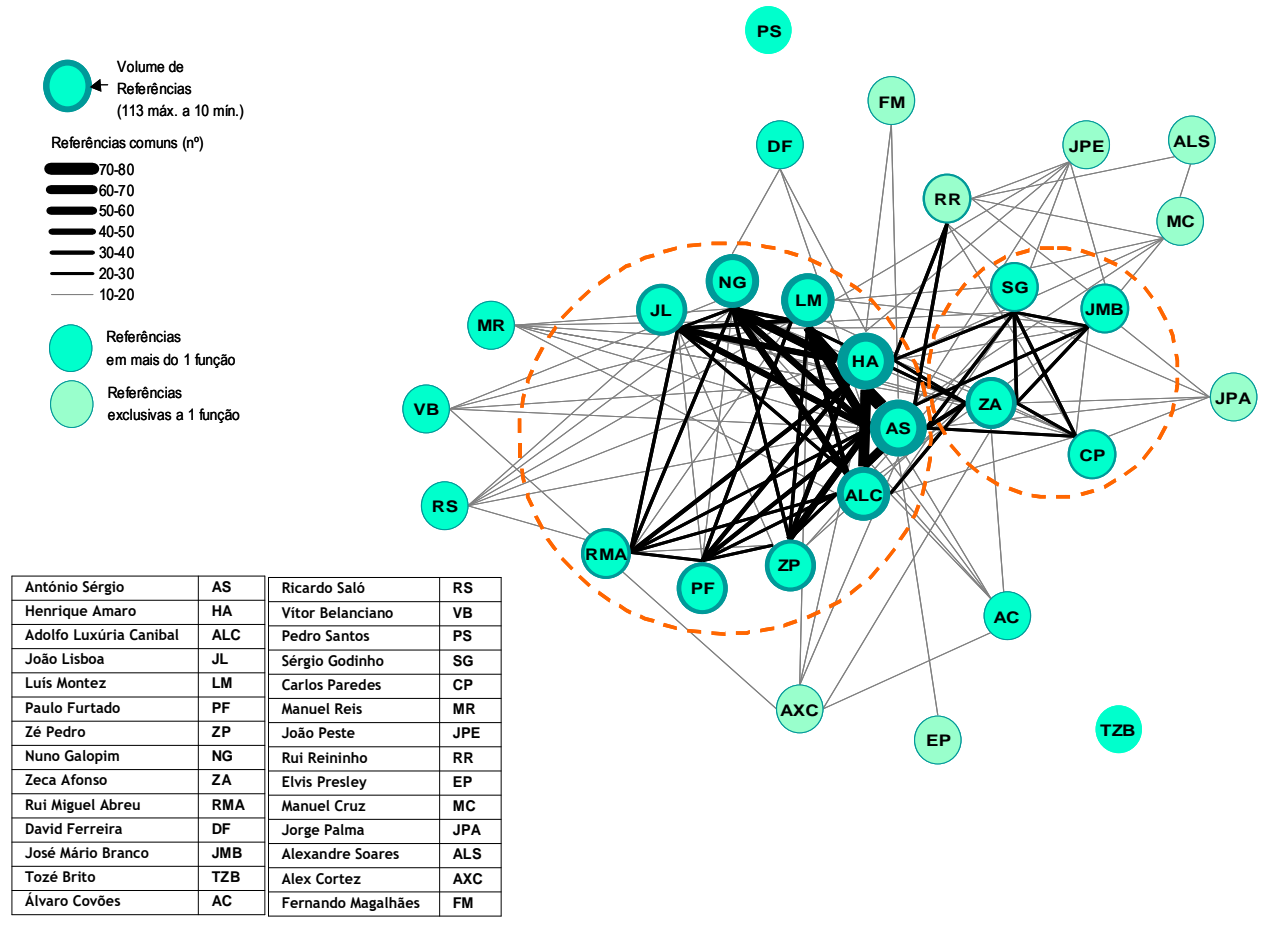

Fonte: Elaboração própria.

A configuração dos principais agentes no subcampo do rock alternativo também invoca elementos importantes (Figura 3). Talvez seja a estrutura poliédrica mais relevante. Esta estrutura mantém dois grupos no seu núcleo. É composto por atores-chave (músicos e agentes dos media) no surgimento do subcampo do rock alternativo em Portugal, em meados da década de 80: António Sérgio ${ }^{41}$, Henrique Amaro ${ }^{42}$, Adolfo Luxúria Canibal43, João Lisboa ${ }^{44}$, Luís Montez45, Paulo Furtado46, Zé Pedro47, Nuno Galopim48, Rui Miguel Abreu 49 (por ordem decrescente de número de referências,

\footnotetext{
41 Locutor e realizador de rádio português, DJ, editor discográfico, especialista e divulgador de música rock, pop e de vanguarda.

42 Locutor e realizador de rádio. Um dos principais divulgadores das novas músicas portuguesas e brasileiras.

43 Vocalista da banda Mão Morta.

44 Crítico de música independente do Semanário Expresso.

45 Fundador e responsável pela promotora Música no Coração.

46 Artista, vocalista e músico blues português cujo nome artístico é The Legendary Tigerman.

47 Foi um músico português, guitarrista e fundador da banda Xutos e Pontapés. Faleceu em 2017.

48 Crítico de música e realizador de rádio.

49 Crítico, blogger, DJ e realizador de rádio.
}

CSOnline - Revista Eletrônica de Ciências Sociais, Juiz de Fora, n. 32 (2020). 
referências estas em mais de um papel) (XXX, 2016). Por exemplo, António Sérgio (considerado o "John Peel português" e responsável pelo início da disseminação da música alternativa) assume o papel de "difusor pioneiro", como invariavelmente mencionado por quase todos os entrevistados. Adolfo Luxúria Canibal, vocalista da banda Mão Morta, é igualmente destacado nessa estrutura, não apenas em termos de volume de referências, mas também por algumas referências comuns relacionadas aos elementos estruturantes do campo. Ele assume o papel de um pêndulo (i. e. mantendo tudo em movimento) e é sem dúvida um ator que detém capital (interno) significativo no meio dos processos de canonização do subcampo do rock alternativo português. Ele também alcançou notoriedade na sociedade portuguesa em geral e no mundo artístico em particular (capital externo). Em linguagem bourdieusiana, essas duas figuras exercem "dominância" no subcampo, concentrando-se nas suas mãos o maior volume de capitais no espaço social-relacional do rock alternativo. Estas considerações permitem mostrar a complexidade das relações que substanciam as estruturas subjacentes de atores, locais, bandas, editoras e promotores que compõem o rock alternativo português, explorada nas secções anteriores deste artigo e aqui apresentada, à luz da teoria dos campos de Bourdieu.

\section{O amor pelo rock alternativo: observações finais}

Definimos o rock alternativo como um subcampo, devido ao alcance limitado de sua extensão temporal e espacial em Portugal, e devido à sua dependência e correlação com o campo da música pop rock em geral. É também um subcampo devido à sua relevância numa análise mais segmentada e plural das atuais manifestações da cultura popular ou de massas. Apresentou-se uma aplicação da teoria bourdieusiana a um segmento artístico e musical específico além do campo literário ou pop rock em geral, operando uma (re)adaptação teórica num esforço para legitimar a análise de um segmento musical que exige abordagens e ferramentas de investigação específicas. Assim, a nossa perspetiva enfatiza tanto a pertinência da perspetiva de Bourdieu quanto a das teorias pós-subculturais sobre contingência contemporânea, pluralidade e instabilidade na produção de processos culturais.

Os processos fundamentais e ferramentas expressivas do rock alternativo português podem ser encontrados por todo o mundo, mas existem, sem dúvida, singularidades locais. O rock alternativo português assumiu características particulares, principalmente 
através dos seus protagonistas e líderes, devido às idiossincrasias históricas do país e às especificidades da indústria musical portuguesa. Após 1986, várias mudanças levaram à criação de um subcampo do rock alternativo dentro do campo mais geral do pop rock. A existência de agentes e estruturas opostas ao establishment explica em grande parte a génese deste subcampo. A democratização política do país, a sua abertura a influências estrangeiras, o aumento da urbanização, a sua adesão à Comunidade Europeia, o surgimento de uma certa 'movida' pósmoderna (principalmente em Lisboa, mas também no Porto), todos contribuíram para o surgimento de um 'segmento alternativo', contrastando os princípios da massificação popular do pop rock. Todos esses elementos facilitaram, além disso, o boom de bandas, editoras independentes, fanzines, programas de rádio, críticos e locais de concertos. As repercussões destas atividades e posições ecoaram no espaço e no tempo até hoje.

\section{Referências Bibliográficas}

BÉRA, Matthieu; LAMY, Yvon. Sociologie de la culture. Paris: Armand Colin Éditeur, 2003.

BOURDIEU, Pierre. O poder simbólico. Lisboa: Difel, 1989

BOURDIEU, Pierre. As regras da arte. Lisboa: Editorial Presença, 1996.

BOURDIEU, Pierre. Questões de sociologia. Lisboa: Fim de Século, 2004.

BOURDIEU, Pierre; WACQUANT, Löic. Réponses. Paris: Editions du Seuil, 1992.

FOWLER, Bridget. Pierre Bourdieu and cultural theory - critical investigations. Londres: Sage Publications, 1997

GUERRA, Paula. A Instável Leveza do Rock: génese, dinâmica e consolidação do rock alternativo em Portugal. 2010. Dissertação (Doutoramento em Sociologia) Faculdade de letras da Universidade do Porto, 2010.

GUERRA, Paula. A Instável Leveza do Rock. Génese, dinâmica e consolidação do rock alternativo em Portugal. Porto: Edições Afrontamento, 2013.

GUERRA, Paula. Keep it rocking: the social space of Portuguese alternative rock (1980-2010). Journal of Sociology, v. 17, p. 615-630, 2016.

HIBBETT, Ryan. What Is Indie Rock?. Popular Music and Society, v. 28, n. 1, p. 55-77, 2005.

MARTIN, Peter J.. Sounds and society: themes in the sociology of music. Manchester: Manchester University Press, 1995.

MENGER, Pierre-Michel. Le Paradoxe du musicien. Le Compositeur, le melomane et l'Etat dans la société contemporaine. Paris: HARMATTAN, 2002. 
O que tem o rock a ver com Bourdieu?

REGEV, Motti. Producing artistic value: the case of rock music. The Sociological Quarterly, v. 35, n. 1, 1994. Disponível em: http://www.jstor.org/stable/4121245. Acesso em: 07 de jul. 2020.

REGEV, Motti. Ethno-national Pop-rock Music: Aesthetic Cosmopolitanism Made from Within. Cultural Sociology, v. 1., n. 3, p. 317-41, 2007.

STANKOVIC, Peter. Appropriating "Balkan": Rock and Nationalism in Slovenia. Critical Sociology, v. 27., n. 3, p. 98-115, 2001.

SZEMERE, Anna. Up from the Underground: The Culture of Rock Music in Postsocialist Hungary. University Park, PA: Pennsylvania State University Press, 2001. 